\title{
Human Bone Marrow-Derived, Pooled, Allogeneic Mesenchymal Stromal Cells Manufactured From Multiple Donors at Different Times Show Comparable Biological Functions in Vitro, and in Vivo to Repair Limb Ischemia
}

\section{Charan Thej}

Stempeutics Research Pvt Ltd

Sudha Balasubramanian

Stempeutics Research Pvt Ltd

Mathiyazhagan Rengasamy

Stempeutics Research Pvt Ltd

Ankita Walvekar

Stempeutics Research Pvt Ltd

Priyanka Swamynathan

Stempeutics Research Pvt Ltd

Swathi Sundar Raj

Stempeutics Research Pvt Ltd

Pradnya Shahani

Stempeutics Research Pvt Ltd

Siddikuzzaman

Stempeutics Research Pvt Ltd

Udaykumar Kolkundkar

Stempeutics Research Pvt Ltd

Raviraja N Seetharam

Stempeutics Research Pvt Ltd

Pawan Kumar Gupta

Stempeutics Research Pvt Ltd

Anish Sen Majumdar ( $\sim$ anish.majumdar@stempeutics.com )

Stempeutics Research Pvt Ltd

\section{Research}

Keywords: Pooled mesenchymal stromal cells, Stempeucel $\circledast$, multiple bone marrow aspirations, angiogenesis, hind limb ischemia

Posted Date: January 18th, 2021

DOI: https://doi.org/10.21203/rs.3.rs-146863/v1

License: (9) (7) This work is licensed under a Creative Commons Attribution 4.0 International License. Read Full License 


\section{Abstract}

Background: We have previously demonstrated that a pooled population of BM-derived, allogeneic mesenchymal stromal cells (BMMSC), Stempeucel $B-1$, produced under good manufacturing practices (GMP) conditions, showed clinical efficacy and safety in patients suffering from critical limb ischemia (CLI) due to Buerger's disease. While Stempeucel ${ }^{\circledR}-1$ is currently used for $\mathrm{CLI}$ and other clinical indications, we wanted to ensure that the product's continuity is addressed by developing and characterizing a second-generation of pooled product (Stempeucel $\AA-1 \mathrm{~A}$ ), manufactured identically from a second BM aspirates of the same three donors after a two-year interval.

Methods: The two versions of Stempeucel ${ }^{\circledR}$ were manufactured and subjected to gene and protein expression analysis. The nature of various growth factors/cytokines secreted, and immunomodulatory activity of these two cell populations were compared directly by various in vitro assays. The preclinical efficacy of these two cell types was compared in an experimental model of hind limb ischemia (HLI) in BALB/c nude mice. The reversal of ischemia, blood flow and muscle regeneration were determined by functional scoring, Laser Doppler Imaging and immunohistochemical analyses.

Results: Qualitative and quantitative analyses of genes and proteins involved in promoting angiogenic activity and immune regulatory functions revealed high levels of correlation between Stempeucel ${ }^{\circledR}-1$ and Stempeucel ${ }^{\circledR}-1$ A cell populations. Moreover, i.m administration of these two cell products in the ischemic limbs of BALB/c nude mice showed significant repair (>70\%) of toe and foot necrosis, leading to improved ambulatory function and limb salvage. Furthermore, a biodistribution kinetics study showed that Stempeucel®-1 was mostly localized in the ischemic muscles of mice for a significantly longer time compared to normal muscles, thus playing an essential role in modulating and reversing HLI damage.

Conclusions: This study shows that with a reproducible manufacturing procedure, it is possible to generate large numbers of pooled mesenchymal stromal cells from human bone marrow samples to establish product equivalence. We conclude from these results that, for the first time, two pooled, allogeneic BMMSC products can be repeatedly manufactured at different time intervals using a two-tier cell banking process with robust and comparable angiogenic properties to treat ischemic diseases.

\section{Background}

In recent years, therapeutic angiogenesis has been achieved by the delivery of proangiogenic factors either by gene delivery or cell therapy [1]. The cell-based approach has gained significant momentum in the management of peripheral arterial disease (PAD). A variety of cells are known to possess angiogenic functions such as $\mathrm{CD} 34^{+}$hematopoietic stem cells (HSC) [2], bone marrow mononuclear cells (BMMNC) [3], endothelial progenitor cells (EPC) [4], mesenchymal progenitor cells (MPC) [5] and mesenchymal stromal cells (MSCs) [6]. So far, BMMNCs, EPCs and MSCs have been shown to ameliorate or reduce the effect of limb ischemia by improving amputation-free survival, ankle-brachial index $(\mathrm{ABI})$, transcutaneous oxygen pressure $\left(\mathrm{TcPO}_{2}\right)$, ulcer healing and reduced rest pain to variable extents in no-option critical limb ischemia (CLI) patients [3]. Among the tissue sources, bone marrow-derived MSCs (BMMSCs) expansion method is well established in various laboratories and is thoroughly characterized as a result of which BMMSC are the principal source of MSCs for the majority of preclinical and clinical studies conducted so far [7][8]. In addition, positive efficacy data have also been observed with adipose tissue-derived MSC (ADSC), placenta-derived MSC (PDMSC), Wharton's jelly-derived MSCs (WJ-MSC) and MSCs differentiated from pluripotent stem cells for various disease indications including CLI [9]. MSCs obtained from various tissue sources including BMMSC are usually isolated by their plastic adherence property and are generally characterized following the recommendations of the International Society of Cell and Gene Therapy [10] which are expanded in large-scale culture for clinical use. While initial success of MSC administration for the treatment of CLI has been demonstrated in various preclinical and early and late phase clinical trials, consistent production and robust demonstration of efficacy between different manufacturing batches of cells have been recognized as a daunting task for these cell products to take it beyond a certain stage of development [11]. Demonstration of consistent characteristics of a cell therapy product in terms of its in vitro functional attributes and preclinical efficacy and safety in a suitable animal model of limb ischemia has been in demand for the long-term sustainability of the product. Such studies are key to determine the disease-modifying ability of these MSCs successfully.

Our first generation of BMMSC product which has been designated as Stempeucel®-1, is a human bone-marrow-derived, cultured, pooled, allogeneic BMMSC product, obtained from the bone marrow (BM) aspirates of several consenting donors [12][13]. The pooling of bone marrow-derived MSCs from three individual donors would presumably eliminate variability seen with individual BMMSC donors and generate a consistent product. Stempeucel ${ }^{\circledR}-1$ has been manufactured from BMMSCs of three healthy consenting donors using a patented two-tier cell banking technology (US8956862). Subsequently, we also published the growth condition, phenotypic and functional characterization, gene expression, differentiation, angiogenic potency and cryopreservation of individual and pooled BMMSCs [14][15][16]. In fact, we have demonstrated that Stempeucel®-1 secretes a wide array of proangiogenic GFs such as vascular endothelial growth factor (VEGF), angiopoietin-1 (Ang-1), stromal-derived factor 1a (SDF-1a), interleukin-8 (IL-8), IL-6, hepatocyte growth factor (HGF) and transforming growth factor $\beta 1$ (TGF $\beta 1$ ) consistently in all batches of Stempeucel $\circledast$-1 [17]. Amongst these factors, VEGF was found to be secreted in a reproducible range in several large-scale expanded batches of Stempeucel ${ }^{\circledR}-1$. Further, we elucidated the mechanism of action (MoA) of Stempeucel ${ }^{\circledR}-1$ population to establish the functional implications of VEGF secretion to directly demonstrate the angiogenic properties of Stempeucel ${ }^{\circledR}$ which is mediated predominantly by VEGF in vitro [17]. The therapeutic angiogenic potential of Stempeucel ${ }^{-1}$ was established in a well-accepted preclinical model with the Astrip method of unilateral limb ischemia in athymic BALB/c nude (OlaHsd-Fox1nu) mice [13][18]. We found that intramuscular (i.m) administration of Stempeucel ${ }^{\circledR}$ ameliorated limb necrosis and improved limb function in 28 days [7][12]. We also published the results of our phase II, open-label, nonrandomized, dose-finding study to evaluate the efficacy of Stempeucel ${ }^{\circledR}$ in CLI due to Buerger's disease [13].

Stempeucel ${ }^{\circledR}-1$ has been used so far to carry out clinical trials for $\mathrm{CLI}$ and other disease indications. To further expand the life span of an efficacious cell therapy product, we manufactured the second generation of Stempeucel ${ }^{\circledR}$ known as Stempeucel ${ }^{\circledR}-1 A$ from the same set of donors at a different time interval and compared its cellular and molecular characteristics with those of Stempeucel $®-1$. In this article, we show the similarities between the two versions of Stempeucel ${ }^{\circledR}$ for determining some critical attributes that are necessary for demonstrating the efficacy and safety in the limb ischemia model. The collective 
data presented in this manuscript validates our robust manufacturing protocol and show that both the products manufactured from the same donors at an interval of two years possess highly comparable characteristics, including angiogenic function, both in vitro and in vivo.

\section{Methods}

Bone marrow aspiration, preparation of master cell banks, working cell banks and Stempeucel® from two different aspirations from the same donors at different times

The methodology of isolating BM, preparation of master cells bank (MCB), working cell banks (WCB) and preparation Stempeucel ${ }^{\circledR}$ has been published previously [13][15] and has also been patented (US8956862). Briefly, the MCB comprises of BMMSCs derived from individual donors and the WCB comprises a pooled population of BMMSCs. The working cell bank-1 (WCB-1) was prepared from the first BM aspirates from three donors and subsequently, the WCB-1A was prepared from the BM aspirated obtained from the same three donors two years apart. Stempeucel $B-1$ is manufactured from WCB-1 and similarly, Stempeucel ${ }^{\circledR}-1 A$ is manufactured from WCB-1A batch. Stempeucel ${ }^{\circledR}-1$ is formulated and cryopreserved in $85 \%$ Plasmalyte A (Baxter, Illinois, USA) $10 \%$ dimethyl sulfoxide (DMSO) (Sigma Aldrich, Missouri, USA) and 5\% human serum albumin (HSA) (Sigma Aldrich, Missouri, USA) and Stempeucel ${ }^{2}-1 \mathrm{~A}$ is formulated in CS5 (CryoStor 5, Biolife Solutions, Washington, USA). In this study, we evaluated the comparability of the Stempeucel ${ }^{\circledR}-1$ and $1 A$ manufactured from two different WCB batches 1 \& $1 \mathrm{~A}$ and cryopreserved in plasmalyte A and CS5 formulations respectively. The basic criteria for the characterization of Stempeucel $B-1$ and $1 \mathrm{~A}$ are given in supplementary table 1 . The techniques used to characterize Stempeucel $\circledast$ have been published previously [14][15].

\section{Gene expression profiling by microarray and analysis of stempeucel®-1, 1A and human foreskin fibroblasts (HFF)}

Total RNA was isolated using the RNeasy Micro kit (Qiagen, Hilden, Germany) as per the protocol provided by the manufacturer. The quality of the extracted RNA was checked using Nanodrop Spectrophotometer (Thermo Fisher Scientific, Waltham, USA). The OD 260/280 ratio was > 1.9 and OD $260 / 230$ was > 1.8 for all samples. Further, RNA integrity was assessed using 2100 Bioanalyzer (Agilent Technologies Inc, Santa Clara, USA) and RNA 6000 Nano kit. The RIN number of all RNA samples was > 8.0. For each sample, $250 \mathrm{ng}$ of total RNA was amplified and labelled using the Ambion WT Expression Kit (Thermo Fisher Scientific, Waltham, USA) and Affymetrix GeneChip WT terminal labelling kit (Affymetrix, Santa Clara, USA), respectively, according to the protocol provided by the supplier. The labelled second cycle cDNA was processed for further analysis using a previously published method [19]. Unsupervised hierarchical clustering of differentially expressed genes was done using a Euclidian algorithm with Centroid linkage rule to identify gene clusters whose expression levels are significantly reproduced across the replicates.

\section{Immunophenotypic characterization by flow cytometry}

The cells were incubated with the below-mentioned antibodies for half an hour at room temperature, following which the samples were analyzed using the FACS DIVA and WinMDI 2.9 software. The expression levels of CD73, CD105, CD44, CD166, CD90, HLA-ABC, CD34, CD45, HLA-DR, CD40, CD80 and CD86 were analyzed. The details and concentrations of the antibodies used are given in supplementary Table 1.

Assessment of in vitro immunomodulatory properties of Stempeucel@-1 and 1A

For immunosuppression assays, a one-way mixed lymphocyte reaction (MLR)assay was performed at a ratio of 1:2.5, 1:5 and 1:10 (peripheral blood mononuclear cells (PBMSC): MSC) as described before [20]. For inflammatory cytokine priming, the MSC growth medium was replaced with $10 \mathrm{ml} /$ flask of complete medium supplemented with Interferon- $\gamma$ (IFN- $\gamma)(10 \mathrm{ng} / \mathrm{ml})$ (Thermo Fisher Scientific, Waltham, USA) and Tumor necrosis factor a (TNF-a) $(15 \mathrm{ng} / \mathrm{ml})$ (Thermo Fisher Scientific, Waltham, USA). After 40 hours of priming, cells were used for the MLR assay. Cell proliferation was measured using a fluorimetric immunoassay kit (Millipore-Sigma, Burlington, USA) for the quantification of Bromodeoxyuridine (BrdU) incorporation, according to the manufacturer's instructions. A one-way MLR cultured in the absence of MSCs would be considered as the $100 \%$ proliferation control. All treatments were performed in triplicates.

\section{Enzyme-linked immunosorbent assay}

Human angiogenic cytokines, VEGF, Ang-1, SDF-1a, IL-6, IL-8, HGF and TGF 31 in the conditioned media (CM) which was collected at the 72-hour time-point as described before [17], were estimated using Enzyme Linked Immunosorbant Assay (ELISA) Kits (R\&D Systems, Minneapolis, USA) according to the manufacturer's directions. The samples were assayed in duplicates. Error bars are expressed as mean value \pm SEM.

In vitro angiogenic activity assessment of Stempeucel@-1 and 1A:

The $\mathrm{CM}$ collected at the 72-hour time point from Stempeucel ${ }^{\circledR}-1$ and $1 \mathrm{~A}$ was used to evaluate three in vitro angiogenic functional assay using human umbilical vein endothelial cells (HUVEC). The HUVEC migration, proliferation and tube formation assays were performed as described in our previous publication [17].

\section{Animal Experiments:}

\section{Animal model and Cell injection procedure}

Unilateral hind limb ischemia was established in 10-12 weeks old BALB/c nude (OlaHsd-Fox1nu) mice as described before [13]. Stempeucel 8 -1 and 1A were administered at a dose of $5 \times 10^{6}$ cells in $50 \mu$ of Plasmalyte $A$ as determined to be the maximum effective dose for Stempeucel $\circledast$ - 1 and published previously [7] or vehicle (Plasmalyte A) was administered by i.m injection using a $26 \mathrm{G}$ needle, around the ligation site, at five different places (approximately $10 \mu \mathrm{l}$ at each 
site), following 2-5hrs post-induction of limb ischemia to enable animals to recover from the trauma of surgery and anaesthesia. All the animals were observed for 28 days at regular intervals.

\section{Limb necrosis and Functional scoring}

The therapeutic effect of Stempeucel ${ }^{\circledR}$ in ameliorating the progression of tissue necrosis was assessed by examining the number of toes necrosed following ligation. Necrotic scoring was performed on days $0,7,14 \& 28$. Similarly, clinical and functional outcome following Stempeucel $\circledast$ treatment was assessed by Tarlov score, ischemic score and ambulatory scores as described before [21].

\section{Blood flow measurement by Laser Doppler Imaging:}

The rate of blood perfusion was measured for both ischemic and normal limb for both cell and vehicle-treated groups using Laser Doppler Imaging system (LDI2, Moor Instruments, UK) at the Department of Pharmacology, PSG College of Pharmacy, Coimbatore, India. The blood flow measurements were expressed as a ratio of the flow in the ischemic limb versus the normal limb.

\section{Dil Labelling of Stempeucel@-1 followed by intramuscular administration for biodistribution analysis}

To examine the persistence of bone marrow-derived MSC in the hind-limb ischemia model in BALB/c nude mice, the cells were stained with Vybrant ${ }^{\text {TM }}$ CM-Dil Cell-Labeling Solution (Thermo Fisher Scientific, Waltham, USA) as described before [22], prior to injecting the cells into the animals. Five million viable cells were resuspended in $50 \mathrm{ul} \mathrm{PlasmaLyte} A$ and injected i.m in both ischemic and normal limbs. Evaluation of signal intensity from CM-Dil labelled cells was performed after cell injection on days 1, 3, 6, 11, 14, 21 and 28 using the In Vivo Imaging System (IVIS) Xtreme Imaging System (Bruker, Massachusetts, USA). The images were quantified using Carestream molecular imaging software. As per the IVIS Xtreme Imaging System guidelines, all the animals were imaged before the cell injection to normalize autofluorescence. Average pixel intensity from each group was calculated from the individual animal's pixel area intensity.

\section{Histopathological evaluation :}

The therapeutic effect of Stempeucel ${ }^{\circledR}$ was also evaluated based on histological analysis of the various muscle sections (adductor, soleus, gastrocnemius, and semimembranosus/gracilus), stained with $\mathrm{H} \& \mathrm{E}$. The stained muscle sections were scored for muscle degeneration, inflammation and muscle necrosis from five separate fields in four distinct areas. Total numbers of each incident of degeneration, inflammation and necrosis were calculated from each group. In animals that presented auto-amputation, the muscles were not collected and in such cases, the maximum histological scoring of 5 (severe) was given for the degeneration, inflammation and muscle necrosis. Muscle fiber area was quantified using QWin Software (Leica Biosystems, Wetzlar, Germany). Immunohistochemical analysis was performed on paraffin-embedded muscle tissue sections (5 $\mu \mathrm{m}$ thickness) of mice using anti-mouse CD31 antibody (Cat no. SAB4502167; Sigma-Aldrich, Missouri, USA), anti-human nuclear antigen (HNA) (Cat no. ab191181; Abcam, Cambridge, UK) and anti-human VEGF antibody (Cat no. ab46154; Abcam, Cambridge, UK). HRP-conjugated secondary antibodies, anti-rabbit IgG (EnVision+, Agilent technologies, California, USA), goat anti-mouse IgG (Cat no.205719; Abcam, Cambridge, UK) and goat anti-rabbit IgG (Cat no. 205718; Abcam, Cambridge, UK) were used for CD31, HNA and VEGF staining respectively. The immunoreactive products were visualized as described before [23]. The evaluation was carried out by blinded Pathologists who were not aware to which group the animals were allocated.

\section{Statistical analysis}

The results were represented as Mean \pm SEM. All the groups were compared by one-way ANOVA followed by Dunnett's multiple comparisons using Graph Pad Prism 5 software. $p<0.05$ was considered a significant change.

\section{Results}

Consistency of gene expression pattern between various batches of Stempeucel®-1 and $1 \mathrm{~A}$ :

Global gene expression profile analysis was used to assess the consistency and comparability of the pooled Stempeucel $\AA^{\circ}$ products obtained from two batches each, of WCB 1 and 1A that were used to manufacture the pooled BMMSC products. Three GMP large-scale batches of Stempeucel ${ }^{\circledR} 1$ and two $1 \mathrm{~A}$ batches were used for analysis after evaluating the quality control parameters. We have performed an unsupervised hierarchical clustering of samples based on the similarity of their gene expression profiles (Fig. 1). It is evident from the condition tree-based analysis on the distance, that an average of $>77 \%$ of the global gene profiles across all the batches manufactured from two different WCBs are similar, indicating a passage independent similarity in the global gene expression profiles of the two pooled BMMSC populations. Gene clustering also clearly showed comparability between the expression profiles of Stempeucel $(\mathrm{B}-1$ and $1 \mathrm{~A}$ batches while each batch related products remain as distinct clusters and the distance between them is non-significant (Fig. $1 \mathrm{~A}$ ). In a scatter plot analysis, we further observed a significantly higher and tighter correlation with an $R^{2}$ value of 0.9827 between Stempeucel ${ }^{\circ}-1$ and $1 A$ batches (Fig. 1B) as compared to that of Stempeucel ${ }^{\circledR}$ and HFF for which the $\mathrm{R}^{2}$ correlation value was observed to be 0.9290 (Data not shown). These results demonstrate that Stempeucel ${ }^{\circledR}$ batches of 1 and $1 \mathrm{~A}$ profiled globally together for the genes analysed.

Next, we analysed the expression profiles of 23 angiogenic genes (Supplementary Table 2) and 33 anti-inflammation genes (supplementary Table 3 ) both of which play important roles in the neoangiogenic and immunoregulatory properties of BMMSC that are imperative in allogeneic stem cell-based therapy (Fig. 1C \& E; supplementary Tables 2 and 3). The average gene expression values of both angiogenic and anti-inflammatory genes were significantly consistent across the five Stempeucel $\AA$ batches ( 3 of 1 and 2 of $1 \mathrm{~A}$ ) while most the genes were expressed at a lower level in the Human Foreskin Fibroblast (HFF) cell line. The microarray data were validated by quantitative real-time PCR across selected key angiogenic genes VEGF, AGPT1, TGF $\beta 1$, HGF and CXCL8/IL-8. A significant correlation was observed in all the gene expression values for VEGF, AGPT1/ANG-1, TGF b1, HGF and CXCL8/IL-8 between 
Stempeucel ${ }^{\circledR}$-1 and 1A (Fig. 1D). Similarly, we also obtained significant correlation for anti-inflammatory genes like Indoleamine 2,3-dioxygenase (IDO), IL-10, vascular cell adhesion molecule (VCAM1), programmed death-ligand 1 (PDL1) and HLA-G between the two Stempeucel ${ }^{\circledR}$ versions (Fig. 1F). The data suggest that both the pooled allogeneic MSC populations exhibit comparable level of gene expression of key angiogenic and immunomodulatory factors by microarray which was further confirmed by RT-PCR analyses.

Assessment of in vitro immunosuppression of alloreactive MLRs by Stempeucel $\mathrm{B}^{-1}$ and $1 \mathrm{~A}$

Immunosuppressive activity of the two versions of Stempeucel ${ }^{\circledR}$ (in two different formulations) was compared by measuring the immunosuppressive activity of Stempeucel ${ }^{\circledR}$ against allogeneic PBMC responder cells in an in vitroMLR assay. The immunosuppressive activity of Stempeucel ${ }^{\circledR}$ was measured from fifteen batches of Stempeucel $\AA$ - 1 and four batches of Stempeucel $\AA$-1A, at different stimulator to responder ratios (Fig. $2 A$ ). Greater than $60 \%$ inhibition of Tcell proliferation was observed with Stempeucel $B-1$ while Stempeucel ${ }^{\circledR}-1$ A showed $>70 \%$ inhibition by Mixed Lymphocyte Reaction (MLR) assay (Fig. 2A). However, the difference in the inhibition of T-cell proliferation induced by both versions of Stempeucel $\circledast$ was not found to be significant. The suppressive activity was titrable with decreasing number of MSC, however, moderate to high immunosuppressive activity was observed at 1:2.5, which further titrated out at 1:10 dilution (Fig. 2A). The difference in the MLR activity between the two Stempeucel $\circledast$ products was not found to be significant.

Although both pooled populations of Stempeucel ${ }^{\circledR}$ expressed low levels of Human Leukocyte Antigen DR (HLA-DR), priming of these cells using a cocktail of IFNY and TNFa resulted in significant upregulation of HLA-DR (Fig. 2B). Furthermore, inflammatory cytokines primed BMMSC showed a concomitant increase in their ability to suppress allogeneic MLR, a finding that has been reported in the literature before [24]. However, similar to their unprimed counterparts, no significant difference was observed between Stempeucel ${ }^{\circledR}-1$ and $1 \mathrm{~A}$ (Fig. 2C), thus emphasising the immunological comparability between the two products

Angiogenic properties of Stempeucel $\AA^{-1}$ and $1 \mathrm{~A}$ products:

First, we quantified the levels of the key angiogenic factor VEGF in the CM from both generations of Stempeucel $\circledast$ at 72 hours (Fig. $3 A$ ). The levels of VEGF secreted by Stempeucel $\AA$ - 1 batches $(n=26)$ was found to be $2.8 \pm 1.0 \mathrm{ng} / \mathrm{mL} / 10^{6}$ cells and for Stempeucel $\AA-1 A(n=4)$ it was $3.45 \pm 0.03 \mathrm{ng} / \mathrm{mL} / 10^{6}$ cells. We observed that both Stempeucel ${ }^{\circledR}-1$ and $1 A$ batches secreted $\geq 2 \mathrm{ng} / \mathrm{mL} / 10^{6}$ cells of VEGF which is our potency criteria for qualifying Stempeucel ${ }^{\circledR}$ for CLI indication (Fig. 3A). Similar to VEGF, both Stempeucel ${ }^{\circledR}-1$ and $1 \mathrm{~A}$ also secreted substantial and comparable levels of SDF-1a (Stempeucel ${ }^{\circledR}-1$ : $568.5 \pm$ $2.3 \mathrm{pg} / \mathrm{mL} / 10^{6}$ cells; Stempeucel ${ }^{\circledR}-1 \mathrm{~A}: 738.7 \pm 24.7 \mathrm{pg} / \mathrm{mL} / 10^{6}$ cells) (Fig. 3B), IL-8 (Stempeucel ${ }^{\circledR}-1: 13.3 \pm 0.1 \mathrm{ng} / \mathrm{mL} / 10^{6} \mathrm{cells}$; Stempeucelß-1A: $8.9 \pm$ $0.03 \mathrm{ng} / \mathrm{mL} / 10^{6}$ cells) (Fig. 3 C) and TGF 1 (Stempeucel ${ }^{\circledR}-1: 1.15 \pm 0.01 \mathrm{ng} / \mathrm{mL} / 10^{6}$ cells; Stempeucel $\circledast-1 \mathrm{~A}: 1.36 \pm 0.01 \mathrm{ng} / \mathrm{mL} / 10^{6} \mathrm{cells}$ ) at $72 \mathrm{hours}$ (Fig. 3D). Next, the functional activity of the pooled cells was evaluated using the CM-derived from three batches of Stempeucel $\AA_{-1}$ and $1 \mathrm{~A}$ by looking at their ability to induce migration, proliferation and endothelial tube formation in HUVEC in vitro. We observed little or no difference in the induction of HUVEC migration activity between the two versions of Stempeucel ${ }^{\circledR}(P=0.59)$ and inhibition of migration was observed in the presence of an anti-VEGF mAb (Fig. 3E). Similarly, no difference was observed in the proliferation of HUVECs induced by CM obtained from the two different versions of Stempeucel ${ }^{\circ}(P=$ $0.78)$ (Fig. 3F) and their ability to induce tube formation activity $(P=0.79)$ (Fig. 3G). Both these activities were significantly abrogated (Proliferation $>95 \%$; Tube formation - >50\%) [Figure 3F; Fig. 3 G (Panels a, b)] by the neutralizing anti-VEGF mAb. The results obtained using positive control EGM medium and negative control medium are shown in Figs. 3E, F and G. The overall results presented here showed a significant correlation in the angiogenic potency of Stempeucel ${ }^{\circledR}-1$ and $1 \mathrm{~A}$ in all three functional assays (Fig. 3).In summary, the two products manufactured from the same three donor-derived cell pools demonstrated equivalent angiogenic function in vitro.

Stempeucel ${ }^{\circledR}$ administration improves limb functionality and protects from foot necrosis in a mouse model of limb ischemia:

As described previously [13], limb necrosis and muscle damage were clearly observed at day 7 after ischemia induction in the vehicle control and the two Stempeucel ${ }^{\circledR}$ treatment groups. Auto-amputation was evident in the vehicle control group on day 14 (Fig. 4A). In fact, $70-80 \%$ of animals treated with Stempeucel $\AA_{-1}$ and $1 \mathrm{~A}$ showed marked protection of limbs from ischemia and only minor toe necrosis was noticed on day 28 (Fig. $4 \mathrm{~A}$ ). However, two animals in Stempeucel ${ }^{\circledR}-1$ treatment group and one animal in Stempeucel ${ }^{\circledR}-1 \mathrm{~A}$ group did show foot necrosis (Supplementary Table 4). Significant improvement in limb function (Fig. 4B) and protection from limb necrosis (Fig. 4C) was comparable between the animals receiving Stempeucel $B$ - 1 and Stempeucel $\AA$ - 1 A, although the two cell populations were cryopreserved in different formulations. Moreover, these functional and pathological changes observed with the vehicle control animals significantly improved when the animals were treated with Stempeucel $(\mathrm{B}-1$ and $1 \mathrm{~A}$ (Fig. 4C). However, no differences observed in both ambulatory score $(P>0.05)$ (Fig. $4 B)$ and necrotic score $(P>0.05)$ between the two generations of Stempeucel ${ }^{\circledR}($ Fig. $4 C)$. Gross assessment of ischemic severity revealed that $90 \%$ of the animals in the vehicle treatment group underwent spontaneous limb amputation and one animal had severe foot necrosis. In contrast, both Stempeucel $B^{8}$ injected groups demonstrated significant limb repair and salvage (Supplementary Table 4).Majority of the animals in these two groups showed only toe necrosis (Supplementary Table 4) clearly demonstrating equivalent therapeutic efficacy.

Stempeucel ${ }^{\circledR}$ treatment improves ischemia-induced muscle regeneration:

In general, we noticed a significant decrease in the muscle fiber area (Fig. 5A) and muscle weight (Fig. 5B) of LI animals treated with the vehicle. Treatment with Stempeucel ${ }^{\circledR}-1$ and $1 \mathrm{~A}$ offered significant prevention of muscle fiber loss due to ischemia in both adductor and gastrocnemius muscles (Fig. $5 \mathrm{~A}$ ). Similarly, a significant loss in muscle weight was seen in animals treated with vehicle (adductor: $40 \pm 6.2 \mathrm{mg}$ and gastrocnemius: $47 \pm 4.5 \mathrm{mg}$ ), compared to the sham control group of animals (adductor: $64 \pm 6.9 \mathrm{mg}$ and gastrocnemius: $87 \pm 7.8 \mathrm{mg}$ ). Substantial prevention of muscle weight loss was observed in the animals treated with Stempeucel-1® (Adductor: $60 \pm 6.3 \mathrm{mg}$ and Gastrocnemius: $58 \pm 5 \mathrm{mg}$ ) and $1 \mathrm{~A}$ (Adductor: $65 \pm 3.9 \mathrm{mg}$ and Gastrocnemius: $44 \pm 2 \mathrm{mg}$ ) compared to the vehicle control group (Fig. 5B). No significant difference was observed in muscle fiber area (Fig. 5A) or muscle weight (Fig. 5B) between animals treated with Stempeucel $\AA-1$ or $1 \mathrm{~A}$. Administration of both the Stempeucel $\AA$ products prevented aggravated muscle atrophy induced by femoral artery ligation suggesting that pooled BMMSCs induced muscle regeneration in the affected limbs of the treated animals. As expected, sham control animals did not 
exhibit muscle degeneration and necrosis (Fig. 5D). We also observed extensive inflammation, degeneration and necrosis in animals treated with vehicle in comparison to those in the sham group of animals but not in the other three groups (Fig. 5C \& D).

A significant increase in the total mean histology scores (inflammation, degeneration and necrosis) was also observed with adductor, soleus, gastrocnemius and semimembranous muscle in the vehicle-treated $\mathrm{LI}$ animals when compared to the sham control group (**P $<0.001)$. Importantly, Stempeucel $\AA-1$ and $1 \mathrm{~A}$ treated animals also showed significant improvement in all aspects of muscle regeneration and reduction of inflammation (**P $<0.001)$ when compared to the animals treated with the vehicle (Fig. $5 \mathrm{C}-\mathrm{F}$ ). Further, we observed that muscle tissue from Stempeucel ${ }^{\circledR}$ treated animals had a significant increase in the number of mouse $\mathrm{CD} 31^{+}$cells, which indicates an increase in the capillary density and arteriogenesis or angiogenesis in all muscles compared to the control group ( $p<0.01$ ) (Fig. $5 \mathrm{G}-\mathrm{J}$ ). Also, the number of CD31+ vessels within the muscle fibers were markedly increased in mice injected with both versions of Stempeucel $\circledast$ compared to the vehicle-treated animals (Fig. 5G-J). Engraftment of Stempeucel $\circledast$ was confirmed by positive immunohistochemical staining with human nuclear antigen (HNA) (Fig. 5K-N) and human VEGF (Fig. 50-R) in the ischemic tissues of treated animals (Fig. 5K-N). As expected, the sham control and vehicle-treated muscles were devoid of HNA (Fig. 5K, L) and hVEGF (Fig. 50, P) positivity.

On day 28, normal blood flow was first observed in hind limbs of sham control animals by laser Doppler perfusion imaging (LDPI) (Fig. 6A). Importantly, almost complete recovery of microvascular blood flow in all five mice injected with Stempeucel $(\mathrm{B}-1(\mathrm{P}<0.01)($ Fig. 6C, E) and 1A (P<0.01) (Fig. 6D, E) was also observed while ischemic limbs of vehicle control animals showed a darker colour with leg necrosis (Fig. 6B, E). Recovery of blood flow, measured by flow flux in the Stempeucel $\circledast$ products administered animals correlated well with increased capillary density (Fig. 6F), suggesting that the MoA of Stempeucel $\circledast$ is through an increase in neoangiogenesis and arteriogenesis (Fig. 6).

Stempeucel $\circledast$ is predominantly localized in the muscle area of ischemic limbs

Overall, the biodistribution pattern of Stempeucel $\circledast-1$ showed that intramuscularly injected cells persisted only at the injected muscle site for the study duration of 28 days and did not get distributed to other organs in detectable intensity in normal or ischemic animals (Fig. 7A). However, signal intensity kinetics revealed differences in the magnitude of the signal in non-ischemic vs. ischemic animals during the study course. The average signal intensity peaked at day 1 in normal animals $(n=6)$ whereas, in ischemic animals $(n=6)$, the intensity was approximately $50 \%$ lower compared to the control mice at the same time-point. While the intensity of the Dil signal from the administered cells in normal mice started to decline rapidly from day 3 onwards, the Dil signal was found to increase in ischemic animals at day 3 and finally peaked at day 6 (Fig. 7B). The Dil signal continued to decline in all control animals progressively from day 3. No or low signal intensity was detected on days 11 and 14 and practically disappeared at the later time points. In contrast, in all ischemic animals, the Dil signal was significantly higher at day $6\left({ }^{*} \mathrm{P}=0.01\right)$ and day $11\left({ }^{\star} \mathrm{P}=0.01\right)$ compared to the non-ischemic animals. The signal intensity remained slightly higher in the ischemic animals compared to the control group for the remainder of the experiment (Fig. 7B). Taken together, these data demonstrate that biodistribution of BMMSC in ischemic animals is kinetically different from that of non-ischemic animals. Since Stempeucel $B-1$ was slated to be used in clinical trials, the biodistribution study was only performed with this first-generation product.

\section{Discussion}

Cell therapy has been established to be a novel therapeutic approach to treat several degenerative diseases including CLI, for which none or few treatment options are available. During the past decade or so, MSCs from various tissue sources have proven beneficial in vascular remodelling in ischemic diseases as well as wound healing [5][25][26]. The main MoA is believed to be operative with MSCs through the secretion of paracrine factors by these cells which can deliver therapeutic signals required to repair and restore the architecture and function of damaged tissues.

Some of the important recommendations of a complex biological cell therapy product are identity, purity, potency and safety of the therapeutic cellular products. According to the FDA requirements, comparability between various batches of products generated at different time-points from one or more tissue donors must be established by both in vitro and in vivo parameters to maintain continuity of the product through validation for a specific disease indication[27]. We, therefore, performed this extensive comparative studies using Stempeucel $\circledast$ manufactured from two different WCBs generated from the MCBs of the same three qualified BM donors at an interval of two years. This was specifically undertaken to determine the robustness of our manufacturing process and to ensure that the pooled BMMSC product, derived from the same donors using our novel technology platform, at different time intervals, retain similar functional efficacy. This is one of the first studies where the comparability and consistency of GMP manufactured product from two different batches of pooled BMMSC-containing WCBs have been demonstrated in terms of their therapeutic potential to repair the damage. Global transcriptional profiling of Stempeucel ${ }^{\circledR}$ batches from the two different WCB lots (WCB-1 and WCB-1A) did not reveal and any significant differences in gene expression profile demonstrating none or little heterogeneity between the two WCBs (data not shown). Additionally, in both Stempeucel ${ }^{8} 1$ and $1 A$, we confirmed the equivalent levels of expression of angiogenic and immunomodulatory genes by microarray and RT-PCR, and the results indeed showed a positive correlation for the selected genes (Fig. 1).

Different batches of Stempeucel $\circledast$ manufactured from the two WCB lots secreted comparable levels of key angiogenic factors namely, VEGF, SDF-1a, IL-8 and TGF $\beta 1$. Importantly, both Stempeucel®-1 and 1A secreted VEGF at a range of $2-5 \mathrm{ng} / \mathrm{mL} / 10^{6}$ cells, which has been determined to be the range of VEGF necessary to qualify every batch of Stempeucel ${ }^{\circledR}$ product [17]. Furthermore, in functional angiogenic experiments, Stempeucel-1 and $1 \mathrm{~A}$, showed similar activity of promoting migration, proliferation and tube formation of HUVECs in vitro. Similarly, another group of investigators demonstrated that VEGF is the key molecule alongside IL-8 and CXCL-5 secreted by Multistem ${ }^{\circledR}$ to promote angiogenic functions in vitro and in vivo [28].Stempeucel ${ }^{\circledR}-1$ \& $1 \mathrm{~A}$ were found to have highly comparable immunomodulatory activity and this activity was found to be dose-dependent. Mimicking the exposure of Stempeucel $B-1$ and $1 A$ to an inflammatory environment in vitro, by exposure to IFNy and TNFa, resulted in similar upregulation of HLA-DR in both versions of Stempeucel $\AA_{\text {.. }}$ HLA-DR upregulation has also been linked to the increased expression of IDO and PGE-2 and these molecules are known to suppress T cell effector function [29][30]. Recently published literature suggests that MSCs isolated from various tissues, when licensed with IFNy, effectively suppress PHA stimulated T cell

Page 6/17 
proliferation and protect themselves from T cell-mediated apoptosis [31]. Consistent with the published literature [24], we found that INFY and TNFa licensing of Stempeucel $\AA^{-1}$ and $1 \mathrm{~A}$ rendered these pooled BMMSCs with augmented allogeneic MLR suppressive activity compared to their unprimed counterparts (Fig. 3).

We have earlier determined that a cell dose of $5 \times 10^{6}$ of Stempeucel- 1 is optimal to repair ischemic limbs in mice, hence we chose to use the same dose to demonstrate product comparability between the two versions of Stempeucel in the same mouse model [7][13]. The results clearly showed significant improvements in limb function, foot and leg necrosis leading to complete limb salvage in a few animals in both the groups. These results were further substantiated by the fact that the administration of these cells completely restored the blood flow in the ischemia-induced animals by 28 days post cell administration. When Norgren et al injected $1 \times 10^{6}$ placenta-derived MSCs (PLX-PAD) into the ischemic limb muscles of mice, they observed $>70 \%$ recovery of blood perfusion into the limbs which were significantly greater than that of the placebo ( $* \star * P<0.0001)$ at 35 days [32]. Similarly, a dose-dependent recovery of blood blow was observed upon injecting human neural stem cells (hNSCs) into the ischemic limbs of immunocompetent CD-1 mice, although, significant recovery was seen with $3 \times 10^{5}$ cells/muscle dose group [33]. Although a direct comparison of our data and the data obtained by PLX-PAD and hNSCs is not possible, it appears that the extent of blood flow throughout the limb with Stempeucel $\circledast$ was higher (as judged by the pathologist to be complete recovery of blood flow). Overall, the in vitro and in vivo functional data generated with Stempeucel ${ }^{\circledR}-1$ and $1 \mathrm{~A}$ demonstrated that the two pooled products are highly comparable.

Interestingly, the biodistribution analysis showed that Stempeucel®-1 was mainly localized at the injection site of the muscle of both normal and ischemic mice (Fig. 7), however, the kinetics of cellular distribution varied significantly between normal and ischemic animals. This difference is likely due to the disease state of ischemic muscles, where the cellular localization peaked at day 6 whereas the average signal intensity peaked in the normal animals within 24 hours of administration. Though the exact reason is not clear, it may be possible that sudden exposure of the BMMSC to the severe ischemic microenvironment might have shunted cell proliferation or induced cell death at the injected tissue site. The surviving cells subsequently proliferated in order to repair the damage caused in the ischemic limb. Intramuscularly injected Stempeucel ${ }^{\circledR}$ persisted only at the site of injection for 28 days and did not get distributed to other organs in both ischemic and normal animals. Although it is difficult to explain the reason for such differences in the kinetics of maximum Dil signal intensity between the two groups is not clear, it is enticing to speculate that Stempeucel stayed longer in ischemic mice until the inflammation subsided and the affected muscles were repaired by blood flow and neoangiogenesis.

\section{Conclusion}

One of the main objectives of this study was to determine the functionality of Stempeucel ${ }^{\circledR}$ obtained from two independently derived cell stocks, produced at different times. The entire comparative study centred around the hypothesis that it is possible to extend the lifespan of the product with comparable in vitro and in vivo properties once the MCB stock and the manufacturing WCB lots are consumed to a large extent by creating a second set of cryopreserved MCBs and WCBs. In order to demonstrate that the pooled BMMSC products obtained from these two versions of WCBs were highly comparable for gene and protein expression important for regulating angiogenesis and repairing ischemia-induced damage in the limb tissue, we conducted a series of studies and established equivalency between the two pooled products, that were manufactured from the same three healthy individuals whose BM tissue was aspirated at two different time points. These observations led us to conclude that pooled cell therapy products of equivalent efficacy can be produced through a robust GMP manufacturing process at different times. Having established that the lifetime of a product can be extended for a considerable period using cell pooling technology, our future aim would be to develop and manufacture the next product that would use BM from three new human donors. Whether certain additional criteria of individual donors-derived BMMSC such as proliferation capacity, angiogenic and anti-inflammatory abilities would enhance the therapeutic potential of a pooled BMMSC product is open to experimentation.

\section{Abbreviations}

ABI Ankle Brachial Index

ADSC Adipose Tissue-derived Mesenchymal Stromal Cells

Ang-1 Angiopoietin-1

BM Bone Marrow

BMMNC Bone Marrow Mononuclear Cells

BMMSC Bone Marrow-derived Mesenchymal Stromal Cells

BrdU Bromodeoxyuridine

CLI Critical Limb Ischemia

CM Conditioned Medium

CS5 CryoStor 5

ELISA Enzyme Linked Immunosorbant Assay

EPC Endothelial Progenitor Cells 
GMP Good Manufacturing Practice

HFF Human Foreskin Fibroblast

HGF Hepatocyte Growth Factor

HLA-DR Human Leukocyte Antigen DR

HLI Hind Limb Ischemia

HNA Human Nuclear Antigen

hNSC Human Neural Stem Cells

HSA Human Serum Albumin

HSC Hematopoietic Stem Cells

HUVEC Human Umbilical vein Endothelial Cells

i.m Intramuscular

IDO Indoleamine 2,3-dioxygenase

IFN-y Interferon $\mathrm{Y}$

IL-6 Interleukin 6

IL-8 Interleukin 8

IVIS In Vivo Imaging System

LDPI Laser Doppler Perfusion Imaging

LI Limb Ischemia

MCB Master Cell Bank

MLR Mixed Lymphocyte Reaction

MoA Mechanism of Action

MPC Mesenchymal Progenitor Cells

MSC Mesenchymal Stromal Cells

PAD Peripheral Arterial Disease

PDL-1 Programmed Death Ligand 1

PDMSC Placenta-derived Mesenchymal Stromal Cells

PLX Placenta-derived Stromal Cell Product

SDF-1a Stromal Cells Derived Factor 1a

SEM Standard Error of Mean

$\mathrm{TcPO}_{2}$ Transcutaneous Oxygen Pressure

TGF $\beta 1$ Transforming Growth Factor $\beta 1$

TNFa Tumor Necrosis Factor a

VCAM Vascular Cell Adhesion Molecule

VEGF Vascular Endothelial Growth Factor

WCB Working Cells Bank

WJ-MSC Wharton's Jelly-derived Mesenchymal Stromal Cells 


\section{Declarations}

\section{Acknowledgements}

This study was funded by Stempeutics Research Private Limited, Bangalore, India. We thank Mr. Manohar BN for approving the funding required for this study.

\section{Competing Interests}

The authors declare no potential conflict of interest

\section{Avilability of data and materials}

All data generated or analyzed are included in this research article.

\section{Author contributions}

CT: Cell expansion and labelling, real time PCR, angiogenic factors estimation and angiogenic assays, supporting in vivo experiments, data analysis and interpretation, and manuscript writing; SB: Microarray data analysis, design of in vitro angiogenic assays, in vivo experiments, manuscript writing; MR: Design and execution of all in vivo experiments and data analysis and manuscript preparation; AW: Cell expansion, real-time PCR correlation of inflammatory genes for microarray; PS: Cell expansion and characterization; SSR: Design and execution of immunomodulatory studies and critical reading; SU: Immunomodulatory experiments; PS: Immunomodulatory experiments; UK: Standardized stability studies for Stempeucel®-1 and 1A; RNS: Responsible for manufacturing and characterization Stempeucel $\AA_{-1} 1$ and 1A; PKG: Preclinical experiment design and critical reading; ASM: Design of studies and data analysis of all in vitro and in vivo experiments. Preparation and final approval of the manuscript.

\section{Consent for publication}

Not applicable

\section{Ethics approval}

Bone marrow aspiration from consenting healthy donors was approved by the Institutional Ethics Committee (IEC) of Kasturba Hospital, Manipal, Karnataka. The reference number for approval is SRPL/CLI/07-08/001.

The animal experimental protocol was approved by the Institutional Animal Ethics Committee (IAEC) (Syngene/IAEC/388/05-2013) of Syngene International animal facility. Animals were maintained at the same facility and all the animal experiments were conducted in the same facility in accordance with the experimental ethics committee.

\section{References}

1. Gianni-Barrera R, Di Maggio N, Melly L, Burger MG, Mujagic E, Gürke L, et al. Therapeutic vascularization in regenerative medicine. Stem Cells Transl Med [Internet]. 2020;9:433-44. Available from: https://onlinelibrary.wiley.com/doi/abs/10.1002/sctm.19-0319

2. Pan T, Wei Z, Fang Y, Dong Z, Fu W. Therapeutic efficacy of CD34 + cell-involved mononuclear cell therapy for no-option critical limb ischemia: A metaanalysis of randomized controlled clinical trials. Vasc Med [Internet]. 2018;23:219-31. Available from: http://journals.sagepub.com/doi/10.1177/1358863X17752556

3. Ponemone V, Gupta S, Sethi D, Suthar M, Sharma M, Powell RJ, et al. Safety and Effectiveness of Bone Marrow Cell Concentrate in the Treatment of Chronic Critical Limb Ischemia Utilizing a Rapid Point-of-Care System. Stem Cells Int [Internet]. 2017;2017:1-16. Available from: https://www.hindawi.com/journals/sci/2017/4137626/

4. Keighron C, Lyons CJ, Creane M, O’Brien T, Liew A. Recent Advances in Endothelial Progenitor Cells Toward Their Use in Clinical Translation. Front Med [Internet]. 2018;5. Available from: https://www.frontiersin.org/article/10.3389/fmed.2018.00354/full

5. Ryu JC, Davidson BP, Xie A, Qi Y, Zha D, Belcik JT, et al. Molecular imaging of the paracrine proangiogenic effects of progenitor cell therapy in limb ischemia. Circulation [Internet]. 2013;127:710-9. Available from: http://www.ncbi.nlm.nih.gov/pubmed/23307829

6. Raval Z, Losordo D. Cell therapy of peripheral arterial disease from experimental findings to clinical trials. Circ Res [Internet]. 2013;112. Available from: http://ang.sagepub.com/content/59/6/705.short\%5Cnhttp://circres.ahajournals.org/content/112/9/1288.short

7. Das AK, Gupta PK, Anoop CH, Balasubramanian S, Majumdar AS. Mesenchymal Stem Cell Therapy for Peripheral Vascular Diseases. Mesenchymal Stem Cell Ther [Internet]. Totowa, NJ: Humana Press; 2013. p. 405-21. Available from: http://link.springer.com/10.1007/978-1-62703-200-1_18

8. Trivedi A, Miyazawa B, Gibb S, Valanoski K, Vivona L, Lin M, et al. Bone marrow donor selection and characterization of MSCs is critical for pre-clinical and clinical cell dose production. J Transl Med [Internet]. 2019;17:128. Available from: https://translational-

medicine.biomedcentral.com/articles/10.1186/s12967-019-1877-4

9. Liew A, O’Brien T. Therapeutic potential for mesenchymal stem cell transplantation in critical limb ischemia. Stem Cell Res Ther [Internet]. $2012 ; 3: 28$. Available from: http://tc.liblink.umn.edu/sfx_local?sid=OVID:medline\&id=pmid:22846185\&id=doi:10.1186\%2Fscrt119\&issn=17576512\&isbn=\&volume=3\&issue $=4 \&$ spage=28\&pages=28\&date=2012\&title=Stem+Cell+Research+\%26+Therapy\&atitle=Therapeutic+potential + for + mesench

10. Dominici M, Le Blanc K, Mueller I, Slaper-Cortenbach I, Marini F, Krause D, et al. Minimal criteria for defining multipotent mesenchymal stromal cells. The International Society for Cellular Therapy position statement. Cytotherapy [Internet]. 2006;8:315-7. Available from: 
http://www.sciencedirect.com/science/article/pii/S1465324906708817

11. George B. Regulations and guidelines governing stem cell based products: Clinical considerations. Perspect Clin Res [Internet]. 2011;2:94-9. Available from: http://www.ncbi.nlm.nih.gov/pubmed/21897884

12. Gupta PK, Chullikana A, Parakh R, Desai S, Das A, Gottipamula S, et al. A double blind randomized placebo controlled phase I/II study assessing the safety and efficacy of allogeneic bone marrow derived mesenchymal stem cell in critical limb ischemia. J Transl Med [Internet]. 2013;11:143. Available from: http://www.pubmedcentral.nih.gov/articlerender.fcgi?artid=3688296\&tool=pmcentrez\&rendertype=abstract

13. Gupta PK, Krishna M, Chullikana A, Desai S, Murugesan R, Dutta S, et al. Administration of Adult Human Bone Marrow-Derived, Cultured, Pooled, Allogeneic Mesenchymal Stromal Cells in Critical Limb Ischemia Due to Buerger's Disease: Phase II Study Report Suggests Clinical Efficacy. Stem Cells Transl Med [Internet]. 2017; Mar;6(3):689-699. Available from: http://www.ncbi.nlm.nih.gov/pubmed/27708131

14. Mamidi MK, Nathan KG, Singh G, Thrichelvam ST, Mohd Yusof NAN, Fakharuzi NA, et al. Comparative cellular and molecular analyses of pooled bone marrow multipotent mesenchymal stromal cells during continuous passaging and after successive cryopreservation. J Cell Biochem. 2012;113:3153-64.

15. Chullikana A, Majumdar A Sen, Gottipamula S, Krishnamurthy S, Kumar AS, Prakash VS, et al. Randomized, double-blind, phase I/II study of intravenous allogeneic mesenchymal stromal cells in acute myocardial infarction. Cytotherapy. 2015.

16. Gottipamula S, Ashwin KM, Muttigi MS, Kannan S, Kolkundkar U, Seetharam RN. Isolation, expansion and characterization of bone marrow-derived mesenchymal stromal cells in serum-free conditions. Cell Tissue Res [Internet]. 2014;356:123-35. Available from:

http://www.ncbi.nlm.nih.gov/pubmed/24448665

17. Thej C, Ramadasse B, Walvekar A, Majumdar AS, Balasubramanian S. Development of a surrogate potency assay to determine the angiogenic activity of Stempeucel®, a pooled, ex-vivo expanded, allogeneic human bone marrow mesenchymal stromal cell product. Stem Cell Res Ther [Internet]. $2017 ; 8: 47$. Available from: http://stemcellres.biomedcentral.com/articles/10.1186/s13287-017-0488-3

18. Goto T, Fukuyama N, Aki A, Kanabuchi K, Kimura K, Taira H, et al. Search for appropriate experimental methods to create stable hind-limb ischemia in mouse. Tokai J Exp Clin Med. 2006;31:128-32.

19. Kim S-H, Kim Y-S, Lee S-Y, Kim K-H, Lee Y-M, Kim W-K, et al. Gene expression profile in mesenchymal stem cells derived from dental tissues and bone marrow. J Periodontal Implant Sci [Internet]. 2011;41:192-200. Available from: http://www.ncbi.nlm.nih.gov/pubmed/21954424

20. Gottipamula S, Muttigi MS, Chaansa S, Ashwin KM, Priya N, Kolkundkar U, et al. Large-scale expansion of pre-isolated bone marrow mesenchymal stromal cells in serum-free conditions. J Tissue Eng Regen Med [Internet]. 2016;10:108-19. Available from: http://doi.wiley.com/10.1002/term.1713

21. Brenes RA, Jadlowiec CC, Bear M, Hashim P, Protack CD, Li X, et al. Toward a mouse model of hind limb ischemia to test therapeutic angiogenesis. J Vasc Surg. 2012;56:1669-79.

22. Rengasamy M, Gupta PK, Kolkundkar U, Singh G, Balasubramanian S, SundarRaj S, et al. Preclinical safety \& toxicity evaluation of pooled, allogeneic human bone marrow-derived mesenchymal stromal cells. Indian J Med Res [Internet]. 2016;144:852-64. Available from:

http://www.ncbi.nlm.nih.gov/pubmed/28474622

23. Rengasamy M, Singh G, Fakharuzi NA, Siddikuzzaman, Balasubramanian S, Swamynathan P, et al. Transplantation of human bone marrow mesenchymal stromal cells reduces liver fibrosis more effectively than Wharton's jelly mesenchymal stromal cells. Stem Cell Res Ther [Internet]. 2017;8:143. Available from: http://www.ncbi.nlm.nih.gov/pubmed/28610623

24. Noronha NC N de C, Mizukami A, Caliári-Oliveira C, Cominal JG, Rocha JLM, Covas DT, et al. Priming approaches to improve the efficacy of mesenchymal stromal cell-based therapies. Stem Cell Res Ther [Internet]. 2019;10:131. Available from: https://stemcellres.biomedcentral.com/articles/10.1186/s13287019-1224-y

25. Heil M, Ziegelhoeffer T, Mees B, Schaper W. A different outlook on the role of bone marrow stem cells in vascular growth: bone marrow delivers software not hardware. Circ Res [Internet]. 2004;94:573-4. Available from: http://www.ncbi.nlm.nih.gov/pubmed/15031269

26. Tateishi-Yuyama E, Matsubara H, Murohara T, Ikeda U, Shintani S, Masaki H, et al. Therapeutic angiogenesis for patients with limb ischaemia by autologous transplantation of bone-marrow cells: a pilot study and a randomised controlled trial. Lancet (London, England) [Internet]. 2002;360:427-35. Available from: http://www.ncbi.nlm.nih.gov/pubmed/12241713

27. Campbell A, Brieva T, Raviv L, Rowley J, Niss K, Brandwein H, et al. Concise Review: Process Development Considerations for Cell Therapy. Stem Cells Transl Med [Internet]. 2015;4:1155-63. Available from: http://doi.wiley.com/10.5966/sctm.2014-0294

28. Lehman N, Cutrone R, Raber A, Perry R, Van'T Hof W, Deans R, et al. Development of a surrogate angiogenic potency assay for clinical-grade stem cell production. Cytotherapy. 2012;

29. Chinnadurai R, Copland IB, Patel SR, Galipeau J. IDO-Independent Suppression of T Cell Effector Function by IFN- -Licensed Human Mesenchymal Stromal Cells. J Immunol [Internet]. 2014;192:1491-501. Available from: http://www.jimmunol.org/cgi/doi/10.4049/jimmunol.1301828

30. Chinnadurai R, Copland IB, Garcia MA, Petersen CT, Lewis CN, Waller EK, et al. Cryopreserved Mesenchymal Stromal Cells Are Susceptible to T-Cell Mediated Apoptosis Which Is Partly Rescued by IFNY Licensing. Stem Cells [Internet]. 2016;34:2429-42. Available from:

http://www.ncbi.nlm.nih.gov/pubmed/27299362

31. Kim DS, Jang IK, Lee MW, Ko YJ, Lee D-H, Lee JW, et al. Enhanced Immunosuppressive Properties of Human Mesenchymal Stem Cells Primed by Interferon-y. EBioMedicine [Internet]. 2018;28:261-73. Available from: http://www.ncbi.nlm.nih.gov/pubmed/29366627

32. Norgren L, Weiss N, Nikol S, Hinchliffe RJ, Lantis JC, Patel MR, et al. PLX-PAD Cell Treatment of Critical Limb Ischaemia: Rationale and Design of the PACE Trial. Eur J Vasc Endovasc Surg [Internet]. 2019;57:538-45. Available from: https://linkinghub.elsevier.com/retrieve/pii/S1078588418308566

33. Katare R, Stroemer P, Hicks C, Stevanato L, Patel S, Corteling R, et al. Clinical-grade human neural stem cells promote reparative neovascularization in mouse models of hindlimb ischemia. Arterioscler Thromb Vasc Biol [Internet]. 2014;34:408-18. Available from: 


\section{Figures}

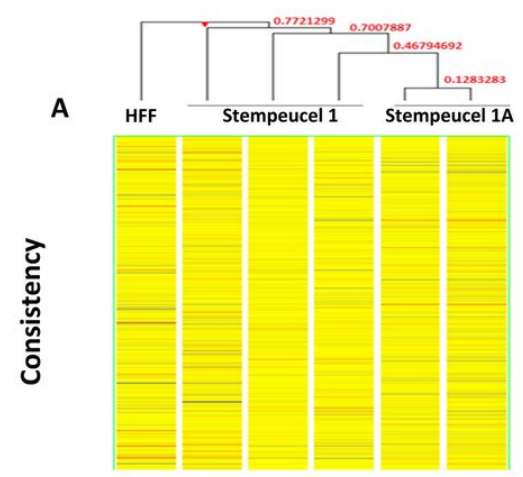

C
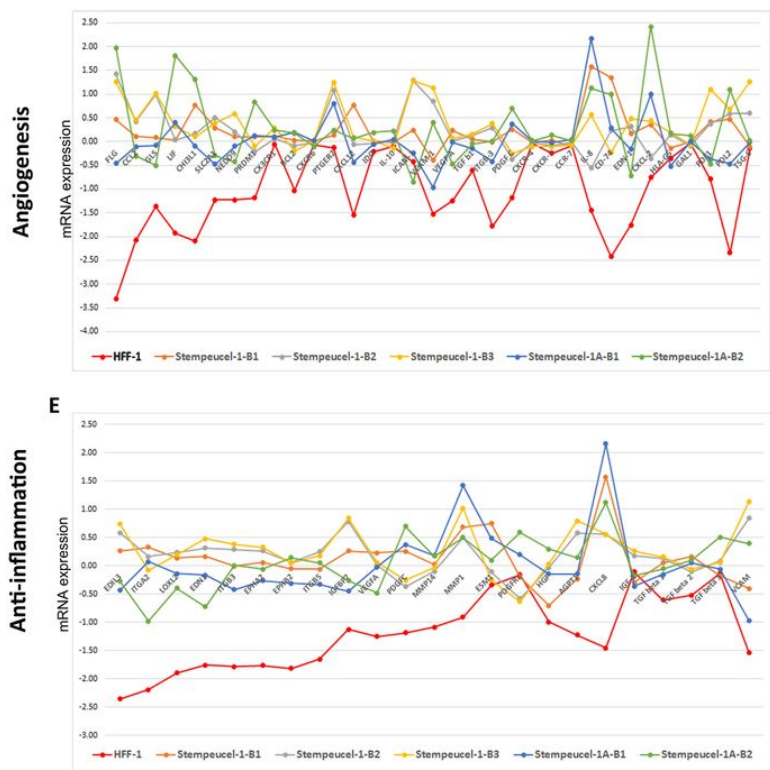

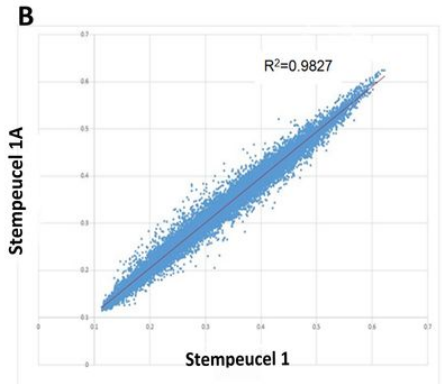

D
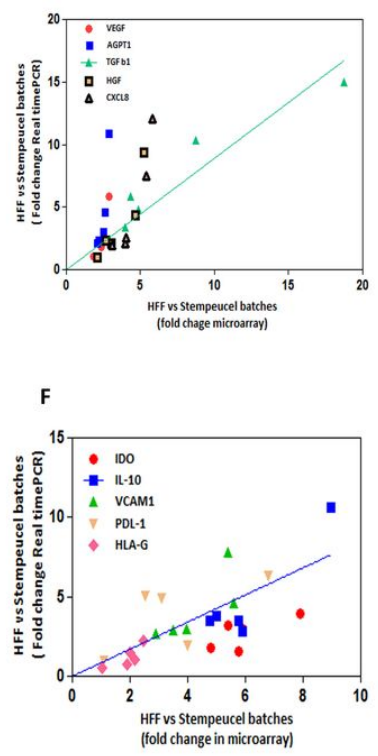

\section{Figure 1}

Gene expression profiling. A, Unsupervised hierarchical clustering/condition tree of samples, HFF-1, three batches of Stempeucel ${ }^{\circledR}-1$ and two batches of Stempeucel $\AA$ - $1 A$ together based on the similarity of their expression profiles. It is evident from the condition tree based on the distance that an average of $>77 \%$ of the global profiles of all the stempeutics products is similar compared to the HFF cells indicating a passage independent similarity in global gene expression profiles. B, Analysis of genes expressed by Stempeucel ${ }^{8}-1$ (X-axis) and Stempeucel $\circledast$ - 1 A (Y-axis) with a significantly high correlation of R2=0.9827 in a scatter plot. C, Comparative evaluation of twenty-three angiogenic genes in HFF-1 cell line, three batches of Stempeucel ${ }^{\circ}-1$ and two batches of Stempeucel $\left(\right.$-1A. D, Real-time PCR analysis of five selected angiogenic genes co-expressed across the Stempeucel ${ }^{\circledR}$ batches compared to HFF-1; VEGF ${ }^{*} \mathrm{P}=0.03, \mathrm{AGPT} 1-{ }^{*} \mathrm{P}=0.04$, TGF b1 $-{ }^{*} \mathrm{P}=0.01, \mathrm{HGF}-\mathrm{P}=0.03$ and CXCL8 - *P=0.02. E, Comparative evaluation of thirty-three anti-inflammation genes in HFF1, three batches of Stempeucel $\AA$-1 and two batches of Stempeucel $\circledast$-1A. F, Real-time PCR analysis of five selected anti-inflammatory genes co-expressed across Stempeucel $\circledast$ batches compared to HFF-1; IDO - **P=0.001, IL-10 - **P=0.004, VCAM1 **P=0.002, PDL1 - **P=0.009 and HLA-G - **P=0.002. 

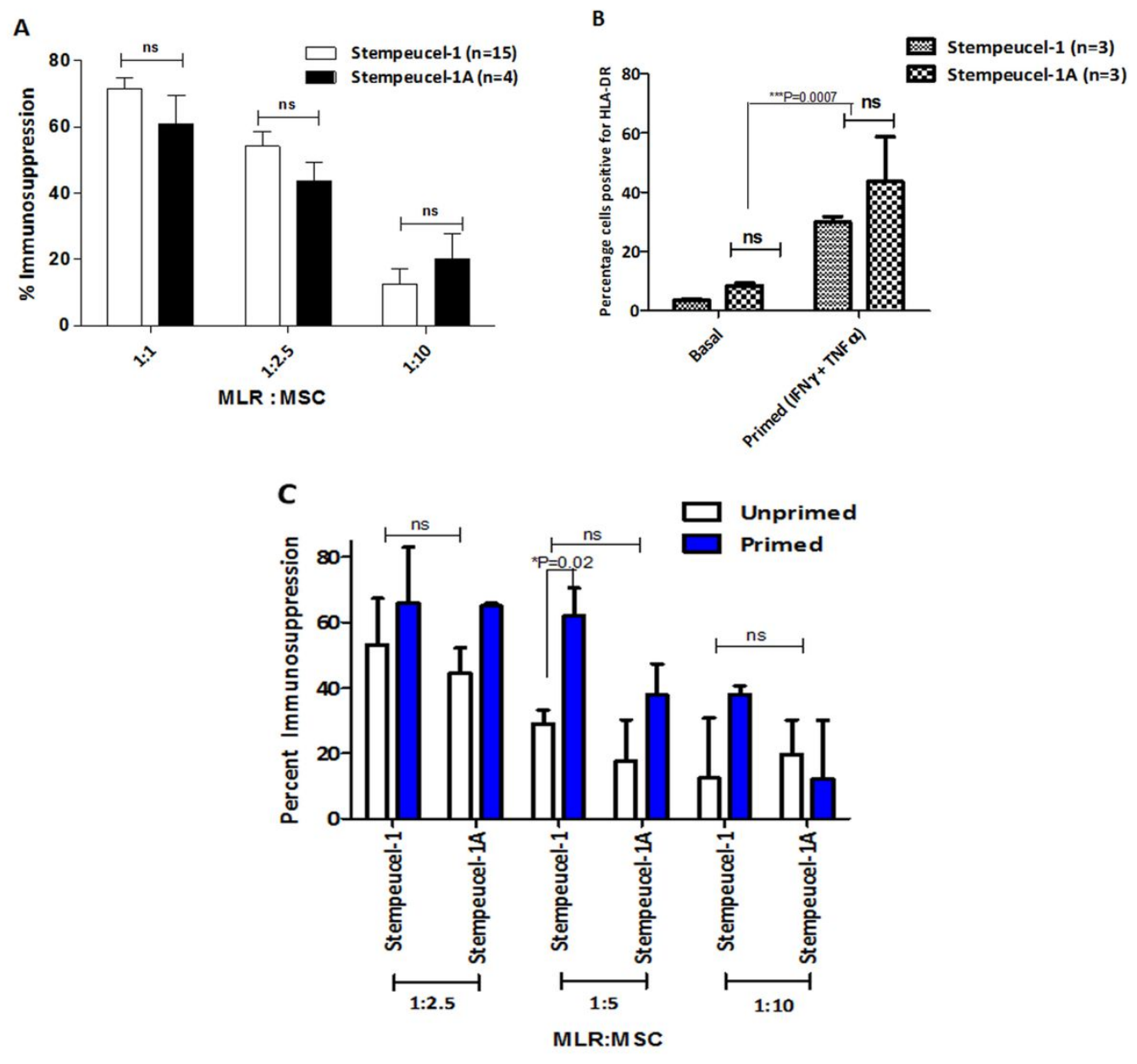

Figure 2

In vitro immunosuppression of alloreactive MLRs by Stempeucel ${ }^{\circledR}-1$ and $1 \mathrm{~A}$. A, Suppression of MLR by mitomycin C-arrested Stempeucel ${ }^{B}-1$ ( $\mathrm{n}=15$ ) and $1 \mathrm{~A}$ $(n=4)$ at three MLR: MSC ratios of 1:1, 1:2.5 and 1:10; MLR proliferation and suppression was measured by BrdU incorporation measurement as described in the results. B, Percentage of cells positive for HLA-DR in Stempeucel ${ }^{8}-1(n=3)$ and $1 A(n=3)$ cells at the basal level and after priming with TNFa and IFNY showed significant difference $(* * * \mathrm{P}=0.0007)$. C, Immunosuppression activity was retained in both Stempeucel ${ }^{\circledR}-1$ and $1 \mathrm{~A}$ upon inflammatory priming at three different ratios of 1:1, 1:5 and 1:10. IFNY and TNFa primed, high HLA-DR expressing Stempeucel $\AA-1$ and $1 \mathrm{~A}$ cells did not reduce their immunosuppression capacity and a trend towards higher immunosuppression of by primed cells was seen compared to unprimed controls. Graphs represent mean \pm SD values; ns - Not significant. 


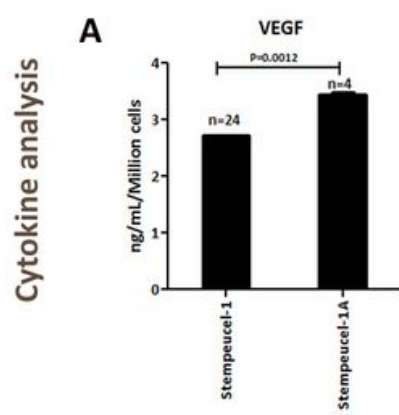

E

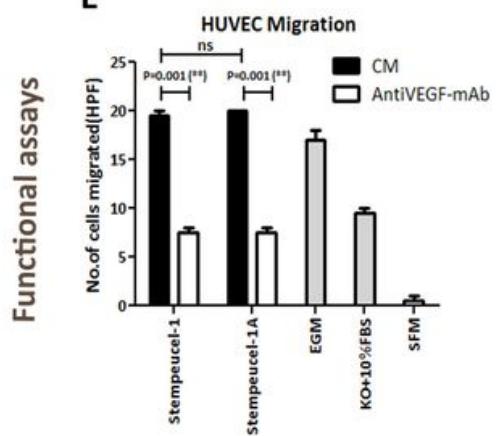

B

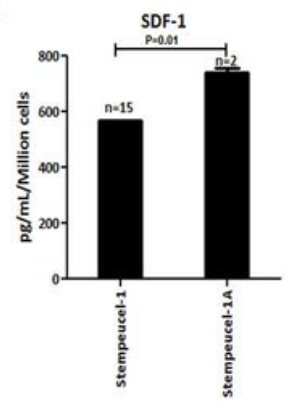

F

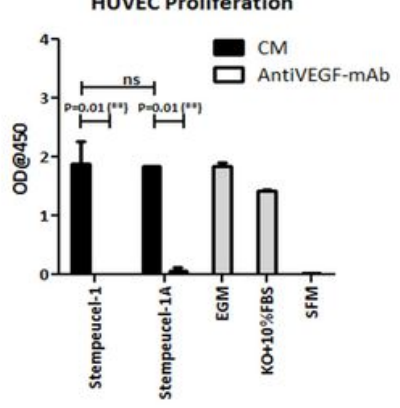

C

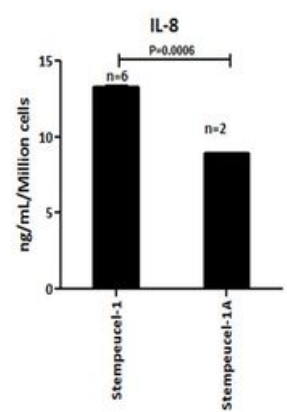

D

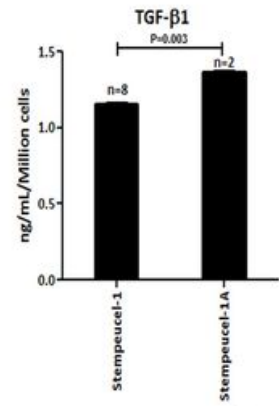

Stempeucel-1

G

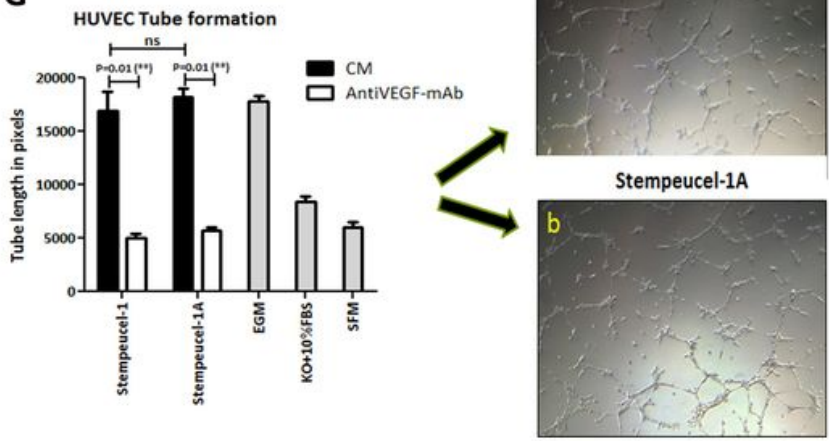

Figure 3

Comparative quantification of angiogenic growth factors A, VEGF (A), B, SDF-1a, C, IL-8 and D, TGF 1 levels in the CM collected at the $72 \mathrm{~h}$ time point from Stempeucel ${ }^{\circledR}-1$ and $1 \mathrm{~A}$ batches. Variation in the levels was observed between the two Stempeucel $\circledast$ versions, VEGF - **P=0.001; SDF-1a -*P=0.01; IL-8 $\star \star \star * P=0.0006 ; T G F \beta 1-* \star P=0.003$. E, The CMs derived from both Stempeucel ${ }^{\circledR}-1$ and $1 A$ promoted HUVECs migration equally. Addition of anti-VEGF $m A b$ in the CMs significantly inhibited HUVECs migration (Stempeucel $\Theta-1=61.6 \%$; Stempeucel $\Theta-1 \mathrm{~A}=61.6 \%, * \star \mathrm{P}=0.001$ ). F, Equivalent HUVEC proliferation was observed with both Stempeucel $\Theta$-derived CM. Significant inhibition in HUVECs proliferation was observed upon neutralizing VEGF in the CMs (Stempeucel $\circledast$ - $1=97.9$, Stempeucel $\Theta-1 A=100 \%$, $* P=0.01)$. G, No significant difference in the HUVECs tube formation efficiency was observed between the CMs derived from Stempeucel $\Theta-1$ and $1 A$ and similar inhibition (Stempeucel $\Theta-1=69.6 \%$, Stempeucel ${ }^{\circledR}-1 A=65.1 \%,{ }^{*} P=0.01$ ) was observed between the two $C M$ s in the presence of anti-VEGF mAb; $a-b$, Similar HUVECs tube forming efficiency was observed with the CMs from both Stempeucel®-1 and $1 A$. Graphs represent mean \pm SEM values. 


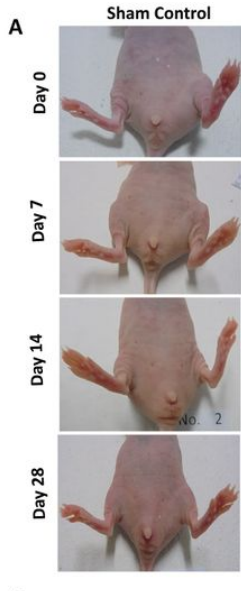

B
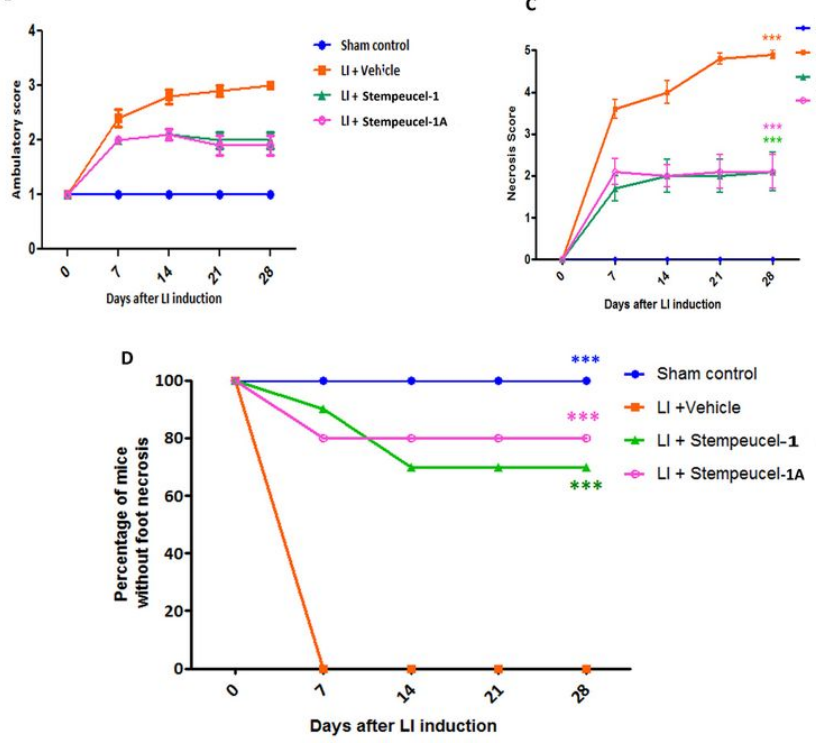

$\mathrm{LI}+$ Stempeucel-1 $\quad \mathrm{LI}+$ Stempeucel-1A
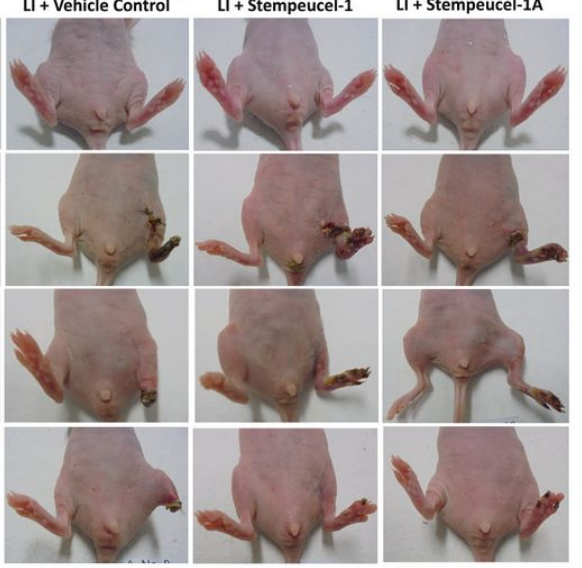

C
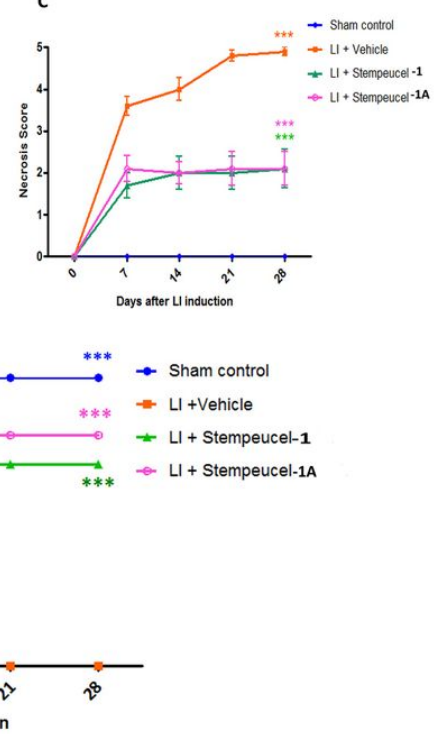

\section{Figure 4}

A, Stempeucel ${ }^{\circledR}$ improves limb functionality and protects from foot necrosis in HLI mouse model. Treatment with both Stempeucel ${ }^{\circledR}-1$ and 1 A can salvage limbs in HLI BALB/c mouse model. Representative photographs of sham control, vehicle control and Stempeucel $\circledast$ treated animals from day 0 to 28.

Stempeucel ${ }^{\circledR}$ improves limb functionality and protects from foot necrosis in HLI mouse model. B, Mean ambulatory and; $C$, necrotic score in sham control, vehicle control, Stempeucel $\AA-1$ and $1 \mathrm{~A}$ treated animals at different time points; necrotic score-Stempeucel $\AA-1$ and $1 \mathrm{~A}-\star \star \star * P<0.001$ versus the vehicle control group. D, Percentage of foot necrosis protection of sham control, vehicle control and Stempeucel $\AA-1$ and $1 \mathrm{~A}$ treated animals at different time points;

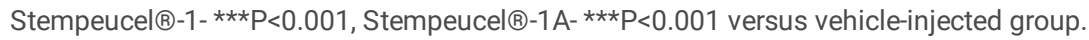




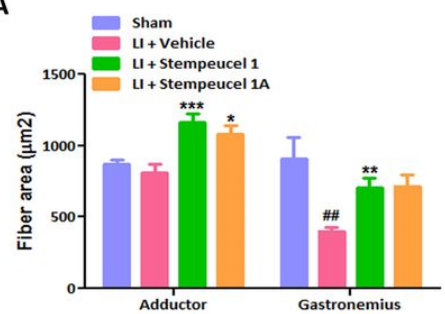

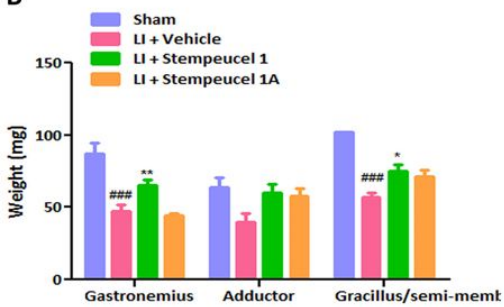
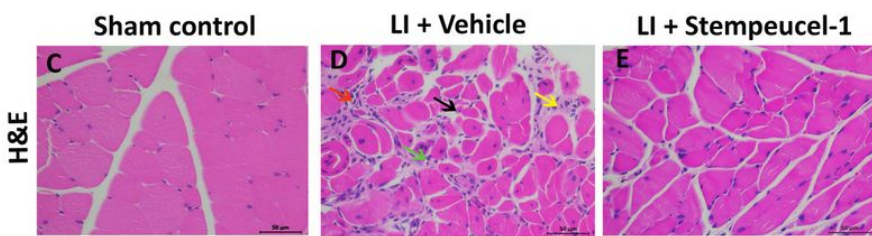

LI + Stempeucel-1A
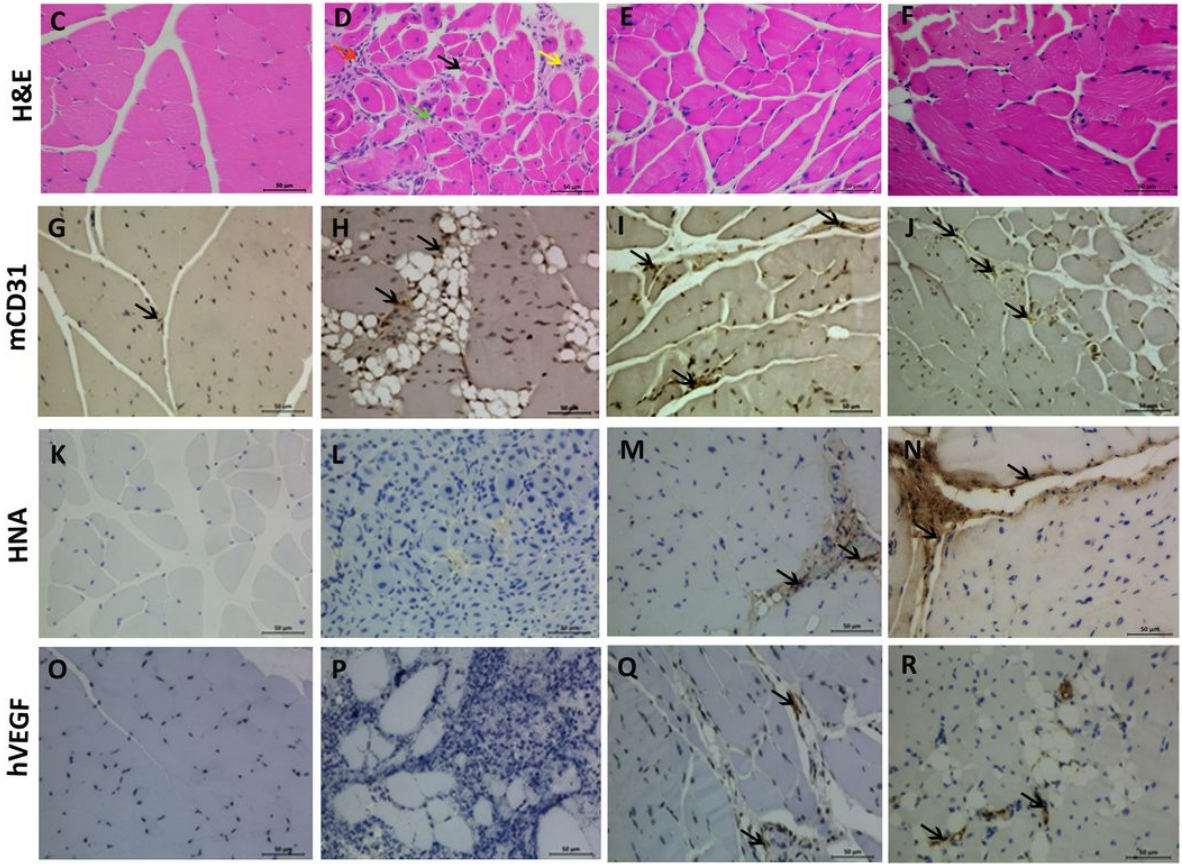

\section{Figure 5}

A similar magnitude of reduction in muscle degeneration and improvement in angiogenesis in ischemic limbs if mice following Stempeucel $B_{1}$ and $1 \mathrm{~A}$ treatment. A, Treatment with Stempeucel ${ }^{\circledR}-1$ and $1 \mathrm{~A}$ has significantly protected muscle fiber loss in adductor and gastrocnemius muscles compared to vehicle control. B, Significant protection from weight loss was observed upon treatment with Stempeucel $\AA_{-1} 1$ and $1 \mathrm{~A}$ compared to the vehicle-treated group. C-F, Histological analysis of muscle section of the sham control, vehicle control and Stempeucel treated groups; Red arrow indicates vacuolar degeneration, green arrow - mononuclear cells infiltration, Yellow arrow - muscle necrosis, and black arrow - muscle degeneration. Intramuscular administrations of Stempeucel ${ }^{\circledR}-1$ and $1 A$ survive in ischemic limb tissue, secrete paracrine factors and recruits or proliferates CD31 positive endothelial cells. Representative images of IHC staining for G-J, mCD31; K-N, HNA; O-R, hVEGF; positive cells in limb muscles of sham control, vehicle control and Stempeucel treated animals at day 28. Photographs were taken at $40 \times$ magnification and Scale bar shows the $50 \mu \mathrm{m}$. 
Sham Control

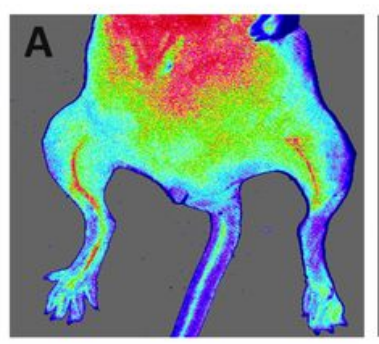

LI + Vehicle

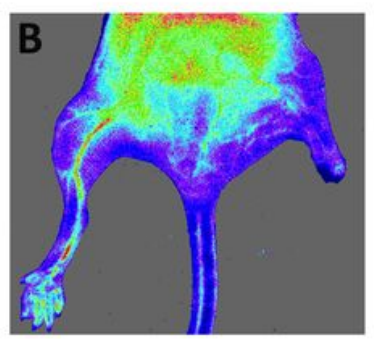

E

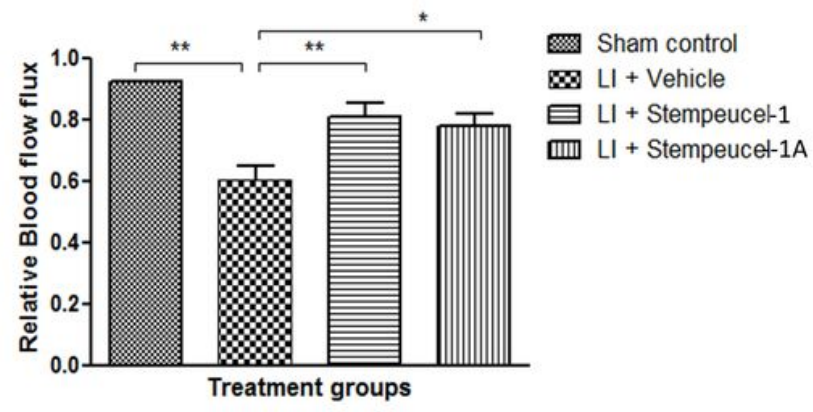

\section{LI + Stempeucel-1 LI + Stempeucel-1A}

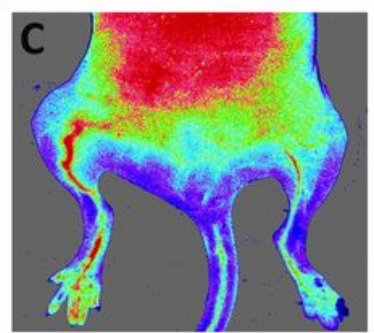

$\mathbf{F}$

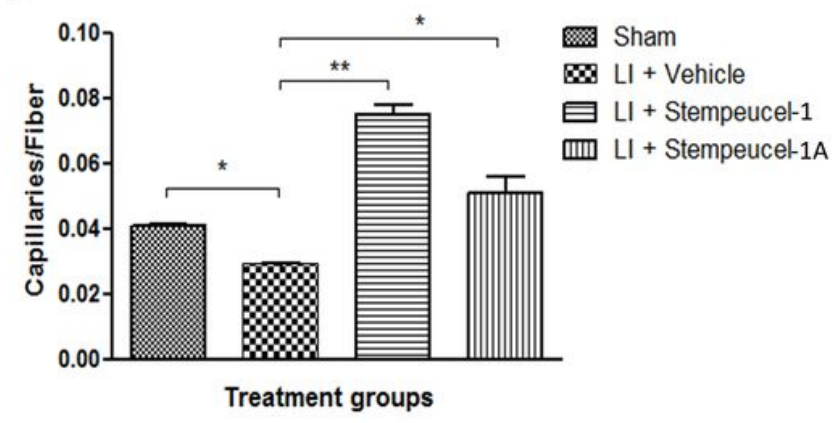

Figure 6

Stempeucel ${ }^{\circledR} 1$ and $1 \mathrm{~A}$ treatment improved blood perfusion and capillary density in ischemic limbs. A-B, Laser Doppler blood flow flux was measured in sham, $\mathrm{LI}+$ Vehicle and LI + Stempeucel ${ }^{\circledR}$ groups at 28 day after $\mathrm{LI}$. \#\#P<0.01, Sham control Vs LI vehicle; ${ }^{* * P}<0.01$, LI vehicle Vs LI + Stempeucel ${ }^{\circledR}-1$; ${ }^{*}<<0.05, \mathrm{LI}$ vehicle Vs LI + Stempeucel ${ }^{\circledR}-1 \mathrm{~A}$. C, Capillary density at day 28 increased significantly in Stempeucel ${ }^{\circledR}-1(* * \mathrm{P}<0.001)$ and Stempeucel ${ }^{\circledR}-1 \mathrm{~A}(* * \mathrm{P}<0.01)$ treated animals compared to vehicle-treated animals. Values are expressed as Mean \pm SEM. Scale Bar $=50 \mu m, 40 \times$ magnification. 


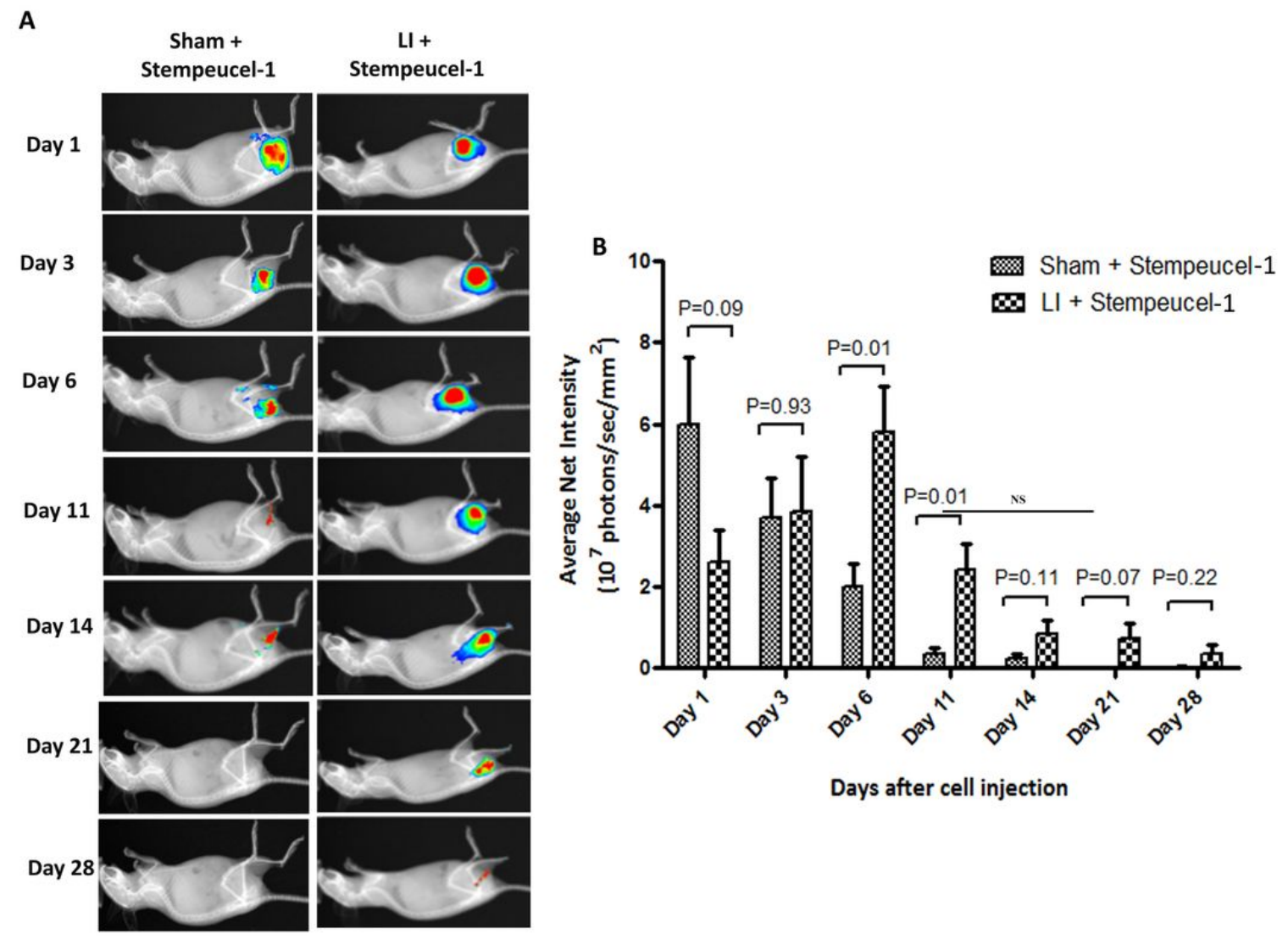

\section{Figure 7}

Biodistribution kinetics of Stempeucel ${ }^{\circledR}-1$ in sham and ischemia-induced BALB/c nude mice. (A): Heat map of Dil labelled areas in the limb muscle of sham control and ischemic animals at various time points after Stempeucel ${ }^{8}$ injection. RGB Scale - 1×107-10×107 photons/sec/mm2. (B): Graphical representation of the average net intensity of Dil labelled cells in the limb muscles of sham and ischemic animal groups on day 1 , day 3 , day 6 , day 11 , day 14 , day 21 and day 28 (end of the experiment). Significantly higher intensity of Dil signal was observed in the ischemia-induced animal group on day 6 and 11 ( $\mathrm{*}=0.01$ ) compared to that of the sham group.

\section{Supplementary Files}

This is a list of supplementary files associated with this preprint. Click to download.

- SupTable1.docx

- SupTable2.docx

- SupTable3Copy.docx

- SupTable4.docx 